\title{
MAURIAC SYNDROME WITH CELIAC DISEASE: RARE ASSOCIATION
}

\section{Gutch Manish*1}

Md (Medicine), D.M (Endo), Assistant Professor, Department of Medicine King George's Medical College, Lucknow, U.P, India

E-mail - manish07gutch@gmail.com

\section{Saransh Singh ${ }^{2}$, Annesh Bhatacharya ${ }^{3}$, Harendra Singh ${ }^{4}$}

Senior Resident, Dept of Medicine, King George's Medical College, Lucknow, U.P, India

\section{Kumar Sukriti ${ }^{5}$}

Assistant Professor, Department of Radiodiagnosis King George’s Medical College, Lucknow, U.P, India

\section{Rungata Sumit ${ }^{6}$}

Md (Medicine), D.M (Gastro), Assistant Professor, Department of Medicine King George's Medical College, Lucknow, U.P, India

Abstract: - Growth failure in type 1 Diabetes Mellitus can occur for several reasons. Mauriac syndrome is a rare cause of severe growth failure in type 1 Diabetes Mellitus. The classical severe presentation of Celiac Disease rarely occurs in type 1 Diabetes Mellitus patients, but more often patients have few/mild symptoms of Celiac Disease or are completely asymptomatic (silent CD). In fact diagnosis of Celiac Disease is regularly performed by means of the screening in type 1 Diabetes Mellitus patients.There may be different forms and etiologies involved in Mauriac syndrome. We hereby report a case of Mauriac syndrome in type 1 Diabetes Mellitus with simultaneous celiac disease which is very rarely reported.

Keywords: Mauriac syndrome, Celiac Disease, Type 1 Diabetes Mellitus

\section{Introduction:}

The association of dwarfism, obesity and hepatomegaly in patients with insulindependent diabetes mellitus (T1DM) is known as Mauriac syndrome. Its presenting features include obesity, hepatomegaly, elevated transaminase levels and cushingoid facies [1], and is generally associated with poor glycemic control in adolescents. The physician should have a high index of suspicion regarding the development of Mauriac syndrome if uncontrolled T1DM is associated with growth failure and delayed puberty, since these changes are reversible with proper glycemic control. [2]Celiac Disease (CD) occurs in patients with Type 1 DiabetesMellitus ranging the prevalence of $4.4-11.1 \%$ versus $0.5 \%$ of the general population. The mechanism of association of these two diseases involves a shared genetic background: HLA genotype DR3-DQ2 and DR4-DQ8 are strongly associated with type 1 Diabetes Mellitus, DR3-DQ2 with Celiac Disease. [9]

\section{Case History:}

A 14-year-old male with a 5 years history of T1DM was admitted for evaluation of growth retardation, abdominal distension and diabetes. He had uncontrolled blood sugar levels despite being compliant on pre-mix insulin (30/70) injection in two divided daily doses of 15 units before breakfast and 10 units before dinner. He had landed up into multiple episodes of documented hypoglycaemia while being on the above regimen. However, there 
was no history suggestive of any episode of diabetic ketoacidosis, and none of his family members were diabetic.

\section{Physical Examination:}

Anthropometric data revealed height $120 \mathrm{~cm}$ ( $<3$ rd percentile), weight $21 \mathrm{~kg} \quad(<3 \mathrm{rd}$ percentile), body mass index $14.58 \mathrm{~kg} / \mathrm{m} 2$, abdominal circumference of $65 \mathrm{~cm}$, MAC of right arm $13 \mathrm{~cm}$ and left arm $12.5 \mathrm{~cm}$, liver span of $18 \mathrm{~cm} . \mathrm{BP} 90 / 60 \mathrm{mmHg}$ right arm supine position.

He had typical cushingoid "moon-like" facies, with thinning of scalp hair, cold extremities and low pitched voice. His abdomen was protuberant, and hepatomegaly was elicited on physical examination. Sexual Maturity Rating (SMR) revealed genital and pubic hair development at "tanner stage 1" for both, i.e. G1 and P1 respectively. Testicular volume was pre-pubertal $(<2 \mathrm{ml})$ as compared with a Praderorchidometer. There was no vitiligo or Hyperpigmentation.

\section{Laboratory Analysis:}

Haemoglobin7.7 g/dl, total protein $7.65 \mathrm{~g} / \mathrm{dl}$, albumin $4.20 \mathrm{~g} / \mathrm{dl}$, triglycerides $391 \mathrm{mg} / \mathrm{dl}$, total cholesterol $122 \mathrm{mg} / \mathrm{dl}$, High density Lipoprotein-cholesterol $21.2 \mathrm{mg} / \mathrm{dl}$ and Low density Lipoprotein-cholesterol $47.7 \mathrm{mg} / \mathrm{dl}$, aspartate aminotransferase $70.6 \mathrm{U} / \mathrm{L} \quad$ (5-45 $\mathrm{U} / \mathrm{L}$ ), alanine aminotransferase76.8 U/L (5-45 U/L) and ALP 283 U/L. Serum calcium was $10.2 \mathrm{mg} / \mathrm{dl}(8.7-10.2 \mathrm{mg} / \mathrm{dl})$ and phosphorus was $5.6 \mathrm{mg} / \mathrm{dl}(2.5-4.3 \mathrm{mg} / \mathrm{dl})$. Blood urea was $14.6 \mathrm{mg} / \mathrm{dl}$ and serum creatinine was 0.55 $\mathrm{mg} / \mathrm{dl}$. Serum sodium was $138 \mathrm{mEq} / \mathrm{l}$ and potassium was $3.75 \mathrm{mEq} / \mathrm{l}$ and serum osmolality was $275 \mathrm{mOsm} / \mathrm{kg} \quad(275-295$ $\mathrm{mOsm} / \mathrm{kg}$ ). His $24 \mathrm{~h}$ urinary protein excretion was $1512 \mathrm{mg}$ (< 150mg/day). His thyroid profile T3-1.09, T4-29.15 and TSH-3.52, HbA1c $=4.46 \%$.Ultrasound study of abdomen showed the presence of fatty infiltration of liver (Grade I) with hepatomegaly. Serum tissue transglutaminase IgA was more than $300 \mathrm{U} / \mathrm{Ml}$ (normal < 12). OGD revealed flattened duodenal mucosal fold and biopsy revealed villous atrophy.
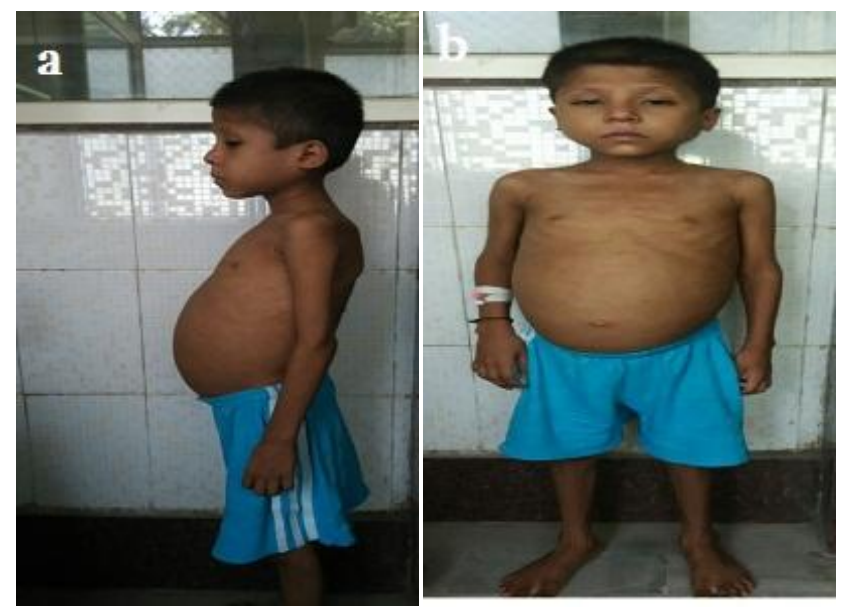

Figure a and b: Type 1 diabetes with prominent abdomen, short stature and celiac disease

Our patient presented with uncontrolled type 1 diabetes mellitus, delayed puberty, severe growth retardation and hepatomegaly, thus enabling a diagnosis of Mauriac syndrome to be made.Upon investigation patient was found to have celiac disease. Few cases have been described of Mauriac syndrome with simultaneous celiac disease

\section{Discussion:}

Mauriac syndrome, the association of dwarfism, obesity and hepatomegaly in patients with Insulin Dependent Diabetes Mellitus (T1DM), occurs most commonly during adolescence, has no sex predilection and has an uncertain aetiology. Most likely a combination of factors comes into play, including inadequate glucose utilization by the tissues, lowered growth hormone and insulin- 
like growth factor-1 (IGF-1) levels,reduced bioactivity of hormones, circulating hormone inhibitors, defective receptor signalling, insulin deficiency leading to poor glycemic control, decreased caloric intake and concurrent Autoimmune diseases. The most commonly associated autoimmune diseases include Addison's disease, hypothyroidism, celiac disease and autoimmune gastritis [3].

In children having DM and growth problem may mean they also have celiac disease. [4] Conversely, recurrent hypoglycaemia can be a sign of celiac disease in people with type 1 DM[5]. Previously, when long-acting insulin was unavailable, delays in growth and puberty were common; with the availability of better treatment modalities, this syndrome is a rare occurrence in the present times.Owing to the frequent absence of symptoms suggestive for gluten-sensitive enteropathy, serological screening for $\mathrm{CD}$ acquires much more importance in T1DM than in other patient settings. The diagnostic accuracy of serological tests for identifying CD in T1DM is very high, but some pitfalls should be considered in the evaluation of antibody tests. tTGA is the first choice test owing to their higher sensitivity for CD ( $98 \%)$, but these markers give a number of false positives at T1DM onset. Duodenal histology remains the gold standard for CD diagnosis in T1DM. The advantages of GFD in T1DM patients with $C D$ are evident with improvement of intestinal and extra intestinal CD-related symptoms, whereas the course of T1DM is not influenced so much by gluten withdrawal. Indeed, it has been demonstrated that hypoglycemic episodes decrease, but at the same time insulin needs increase and HBA1c levels do not improve. Moreover, the protection induced by GFD on the development of lymphoma and other complications in CD patients overcomes some negative effects of the diet, such as the possible development of a metabolic syndrome, which is favoured by the improved intestinal absorption and by a high consumption of commercial gluten-free foods, particularly rich in carbohydrates and lipids.

\section{Conclusion:}

Through Mauriac's syndrome nowadays found to be rare in developed countries, is still prevalent in developing countries. Timely identification of this syndrome can prevent various complication associated with this syndrome.

\section{References:}

1. Mahesh S, Karp RJ, Castells S, Quintos JB. Mauriac syndrome in a 3-year-old boy. EndocrPract 2007;13:63-6.

2. Kim MS, Quintos JB. Mauriac syndrome: Growth failure and type 1 diabetes mellitus. PediatrEndocrinol Rev 2008;5:989-93.

3. Hunger-Battefeld W, Fath K, Mandecka A, Kiehntopf M, Kloos C, Müller UA, et al. Prevalence of polyglandular autoimmune syndrome in patients with diabetes mellitus type 1. Med Klin (Munich) 2009;104:183-91.

4. Bradbury BL, ScarpelloJHB. Recurrenthy poglycemia as the presenting symptom of celiac diseasein a patient with type 1 DM.practdiabtint1999; $16:$ 81-90.

5. Hansen D, Bennedbaek FN, Hansen LK. High prevalence of coeliac disease in Danish children with type I diabetes mellitus. ActaPaediatr 2001; 90 (11) 1238- 1243.

6. Gutch M, Philip R, Saran S, Tyagi R, Gupta KK. Re-emergence of a rare syndrome: A case of mauriac syndrome. Indian J EndocrMetab 2013;17, Suppl S1:283-5. 
7. Camarca ME, Mozzillo E, NugnesR,Zito E, Falco M, Fattorusso $\mathrm{V}$ et al. Celiac disease in type 1 diabetes mellitus. Ital J Pediatr. 2012; 38:10.

8. Lauret E, Rodrigo L. Celiac disease and autoimmune-associated conditions. BioMed research international, 2013:127589. 2013.

9. Gutch M, Kumar S, Saran S, Gupta KK, MohdRazi S, Philip R. Prevalence of autoimmune disorders in pediatrics type-1 diabetes mellitus in western, Uttar Pradesh, India. Int J Med Public Health 2015;5:29-31 